\section{El análisis arqueológico como base de dos propuestas: El Cuarto Real de Santo Domingo (Granada) y el Patio del Crucero (Alcázar de Sevilla)}

\author{
Antonio Almagro GorbeA \\ Escuela de Estudios Árabes. CSIC, Granada
}

\begin{abstract}
Resumen
La investigación arqueológica de los edificios ayuda en muchos casos a desentrañar aspectos que tienen que ver con la esencia misma de la arquitectura pero que muchas veces se perciben como elementos inmateriales: espacio, luz, ... La trascendencia que el conocimiento de esas realidades inmateriales tiene sobre la propia obra arquitectónica y sobre su conservación puede tener distintas concreciones según sean las necesidades que el propio edificio presente. Analizaremos dos tipos de actuaciones. Una de ellas comporta una intervención física sobre el edificio en el que se trata de recuperar la primitiva estructura y configuración sobre la base de desentrañar las sucesivas intervenciones realizadas en el mismo en base a un análisis estratigráfico previo y simultáneo a la propia restauración. En otro caso, esta recuperación resulta imposible no solo por la pérdida de elementos ya irrecuperables, sino por el indudable valor de otras aportaciones históricas que deben ser necesariamente asumidas. En este caso el análisis arqueológico ha llevado una propuesta de recreación virtual de distintas fases históricas que permiten no solo transmitir mejor nuestros conocimientos hacia el público no especializado, sino considerar determinados aspectos que resultan difícilmente abordables con los medios hasta ahora usados y que incluyen la valoración de aspectos perceptivos de los espacios y de las formas.
\end{abstract}

Palabras claves: Análisis arqueológico, reconstrucción virtual, luz, espacio.

\begin{abstract}
Archaeological investigation applied to buildings proves helpful in many cases to unentangle aspects which are crucial to architecture but are often seen as immaterial: light, space... The relative importance of a proper knowledge of those immaterial entities for an architectural work and its conservation may differ upon the needs of the building itself. We will analyze two kinds of performance. One of them entails a physical intervention on a building with the goal of recovering its original structure and configuration through the disentanglement of successive interventions, by means of stratigraphic analysis both previous and simultaneous with the restoration process itself. In the other case, this recovery proves not feasible, not only because recovery of lost elements might be effectively impossible, but also because of the undisputed worth of other historical contributions that must be necessarily taken for granted. In this case, archaeological analysis has brought about a proposal of a virtual recreation of different historical phases that might make it possible not only to present our knowledge to non-specialized audiences in a better way, but also to consider specific aspects which are difficult to approach through the usual methods and which include the appraisal of perceptual aspects of space and form.
\end{abstract}

Key words: Archaeological analysis, virtual recreation, light, space.

\section{INTRODUCCIÓN}

La investigación arqueológica de los edificios ayuda en muchos casos a desentrañar aspectos que tienen que ver con la esencia misma de la arquitectura pero que muchas veces se perciben como elementos inmateriales: espacio, luz,... La trascendencia que el conocimiento de esas realidades inmateriales tiene sobre la propia obra arquitectónica y sobre su conservación puede tener distintas concreciones según sean las necesidades que el propio edificio presente.

Vamos a analizar dos tipos de actuaciones. Una de el las comporta una intervención física sobre el edificio en el que se trata de recuperar la primitiva estructura y configuración sobre la base de desentrañar las sucesi vas intervenciones realizadas en el mismo sobre la base de un análisis estratigráfico previo y después si multáneo a la propia restauración. En otro caso, esta recuperación resulta imposible no sólo por la pérdida de el ementos de los que hemos perdido todo conocimiento, sino por el indudable val or de otras aportaciones históricas que deben ser necesariamente asumidas. En este caso el análisis arqueológico ha llevado una propuesta de recreación virtual de distintas fases históricas que permiten no sólo transmitir mejor nuestros conocimientos hacia el público no especializado, sino considerar determinadas facetas que resultan difícilmente abordables con los medios hasta ahora usados y que incluyen la val oración de aspectos perceptivos de los espacios y de las formas.

\section{EL CUARTO REAL DE SANTO DOMINGO}

Primeramente presentamos la investigación realizada de forma previa y simultánea a la restauración que hemos desarrollado en un monumento de especial interés: se trata del Ilamado Cuarto Real de Santo Domingo (GómezMoreno Martínez, 1996; Pavón Maldonado, 1991; Almagro, Orihuela, 1995, 1997; Orihuela, 1997), monumento muy singular tanto por su ubicación en medio de un jardín preservado desde época islámica en el corazón de la ciudad de Granada, como por tratarse de un edificio anterior a la mayor parte de las construcciones de la Alhambra. Esta investigación se ha desarrollado en dos fases, una como operación previa a la elaboración del proyecto de restauración y otra de modo simultáneo a las obras, que es lógicamente la continuación y complemento de la anterior.

El edificio, transformado en el siglo XIX con la adición de una construcción residencial de escaso val or arquitectónico (fig. 1) y por restauraciones caprichosas y de dudoso criterio, contiene importantes labores de decoración en yeso, pinturas, alicatados, y una hermosa armadu- 


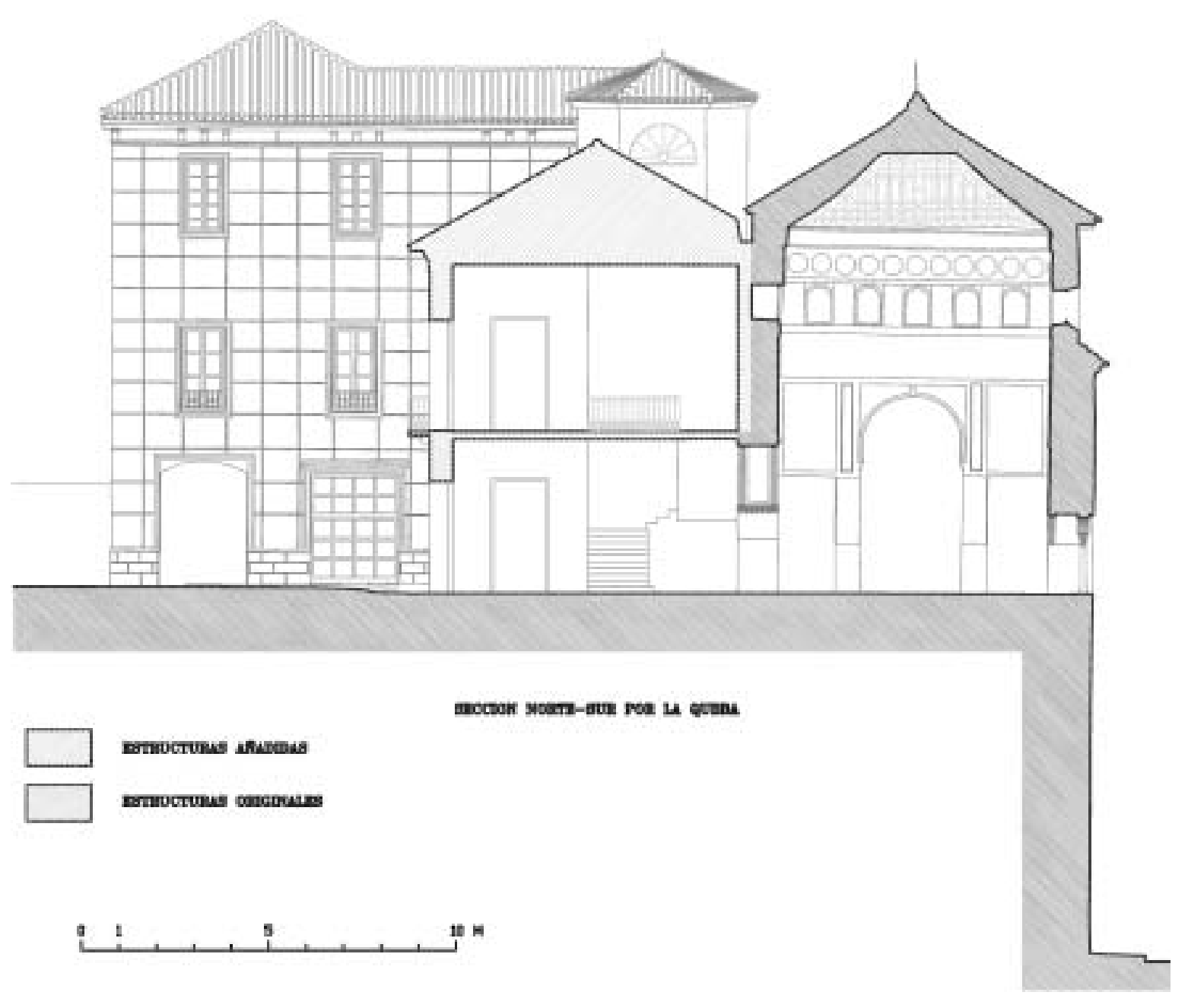

Fig. 1. Sección actual del Cuarto Real de Santo Domingo

ra en el techo también con decoración pintada. Siempre ha despertado la atención de los investigadores por considerarlo el más antiguo testimonio del arte nazarí. Diversos estudios, al gunos de fechas recientes, han planteado hipótesis sobre su forma y apariencia originales aunque sin la base de una investigación arqueológica en profundidad que además nunca se pudo hacer por ser de propiedad privada. Después de su adquisición por el Ayuntamiento de Granada, se planteó su necesaria restauración.

La investigación necesaria para clarificar la forma original del conjunto y la evolución y transformación que ha sufrido a lo largo de su historia, actuación imprescindible y previa a cual quier restauración, no ha precisado de cuantiosas inversiones, pero si el tiempo necesario para que pueda hacerse con la metodología adecuada. La que se describe a continuación ha supuesto un gasto aproximado de sólo un 5 \% del total dela inversión que será necesaria para recuperar el monumento. Como contrapartida se ha demostrado plenamente eficaz para evitar las interrupciones y retrasos en las obras, reformas de proyectos y aumentos presupuestarios que casi siempre ocurren en intervenciones carentes de investigación previa.

Encomendados los análisis previos a la Escuela de Estudios Árabes del $\mathrm{CSIC}^{1}$, se inició un levantamiento planimétrico completo al que se dio comienzo con una planta taquimétrica de todo el jardín y los contornos del edificio. Posteriormente se acometió el levantamiento detallado de la qubba o pabellón islámico, tanto de sus exteriores como de los interiores mediante la utilización de fotogrametría. Para la real ización de esta última parte se contó con un andamio móvil en el que se fijó una guía sobre la que se desplazaba un carro con la cámara foto- 


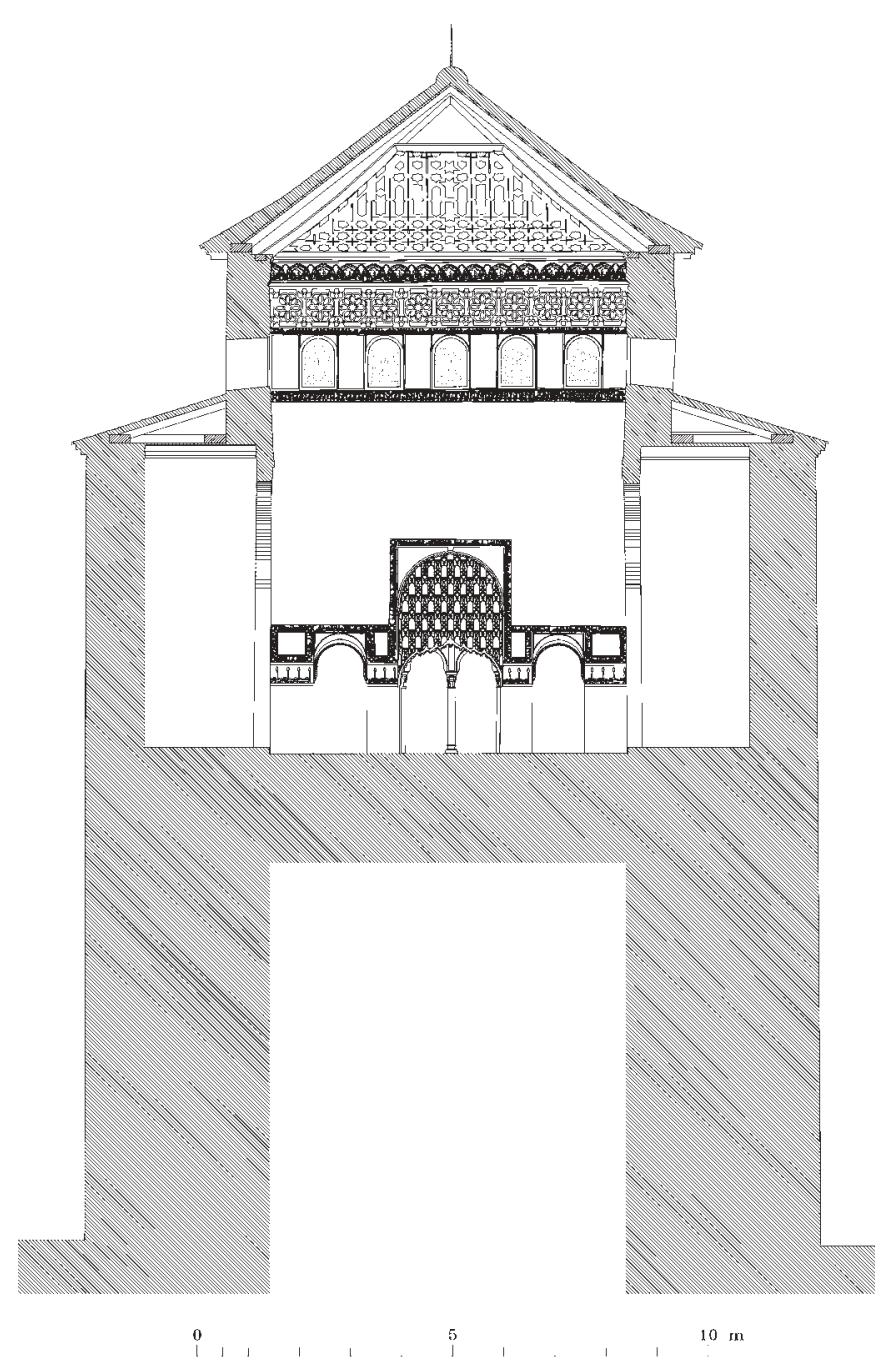

Fig. 2- Sección transversal de la qubba con las alhanías recuperadas.

gráfica. Este dispositivo permitió la obtención de fotografías de un modo veloz y con los requisitos adecuados de recubrimiento de los fotogramas. Los puntos de control se midieron por trisección desde estaciones enlazadas con la red exterior. La restitución ha sido realizada

\footnotetext{
${ }^{1}$ Los trabajos de investigación desarrollados en 1995 se real izaron bajo la dirección de los investigadores Dres. Antonio Almagro y Antonio Orihuela. En la excavación arqueológica colaboró el Proyecto de Arqueología U rbana dirigido desde el Departamento de Prehistoria y Arqueología de la Universidad de Granada, participando como arqué́logos Pablo Casado Millán y J uan Antonio García Granados. En el invierno de 2000 se realizaron otras excavaciones complementarias bajo la dirección de éste último. El estudio de las pinturas y decoración para su restauración fue realizado por Victor M edina Florez, Ana García Bueno y Carmen Rallo Graus. Los estudios de dendrocronología han sido desarrollados por Eduardo Rodriguez Trobajo del IN IA, contándose además con la colaboración de Enrique N uere Matauco para el estudio de la armadura. En la fase de restauración también ha participado activamente en las investigaciones el arquitecto técnico J osé M anuel López O sorio.
}

con el máximo detalle pero codificando la decoración según las distintas tramas ornamentales a fin de poder representar según la escal a de impresión, la cantidad de información adecuada. Para al gunas partes planas como alicatados y pinturas murales se ha utilizado el sistema de restitución monoscópica previo el enderezamiento de las imágenes.

La labor de estudio del monumento ha llevado consigo trabajos de eliminación de enlucidos para identificar las distintas etapas cronológicas y la forma original del edificio así como excavaciones arqueológicas tanto en el jardín como en el interior de la qubba y en el lugar en que se situaba su pórtico. Estas excavaciones han sido igualmente documentadas mediante fotogrametría obteniendo las fotos con un bípode que permite situar la cámara orientada vertical mente hacia abajo a una considerable al tura.

Paral elamente, un equipo de restauradores, analizó las yeserías y zócalos pintados, con objeto de elaborar una propuesta de intervención basada en datos objetivos. Gracias a esta labor se descubrió que los zócal os de los balcones laterales del paramento sur, repintados en los años treinta, mantenían debajo importantes vestigios del modelo original, que reprodujeron con fidelidad.

El estudio inicial de la armadura apeinazada de par y nudillo, que cubre la sala, permitió descubrir defectos técnicos que podrían avalar su construcción por carpinteros andalusíes, normalmente menos experimentados que los castellanos coetáneos. Se tomaron muestras de maderas para su datación por dendrocronología, aunque estos análisis no tuvieron resultados inicialmente, pues las maderas son de pequeñas escuadrías y tienen series de anill os reducidas. No obstante, se constató que una parte importante de la madera utilizada es de cedro, sin duda proveniente de M arruecos.

J unto con estas labores de estudio material, también se ha indagado con dibujos, planos e imágenes pretéritas del edificio, así como con textos y documentos que hacen mención del mismo, como modo de conocer su evolución histórica poniendo en relación esta documentación con la obtenida en el propio monumento.

Gracias a toda esta documentación, se elaboró un proyecto previo que preveía la eliminación del edificio adosado a la qubba en el siglo XIX y la recuperación del jardín con su trazado original. Este proyecto (fig. 2) analizaba la forma y estructura originales del pabel ón con idea de restituirlo a su primitivo estado resolviendo de esa forma muchos de los problemas estructurales que ahora aquejan al edificio (Almagro, Orihuela, 1997).

El análisis detallado y profundo de toda la realidad material del edificio incluyendo un levantamiento plani- 


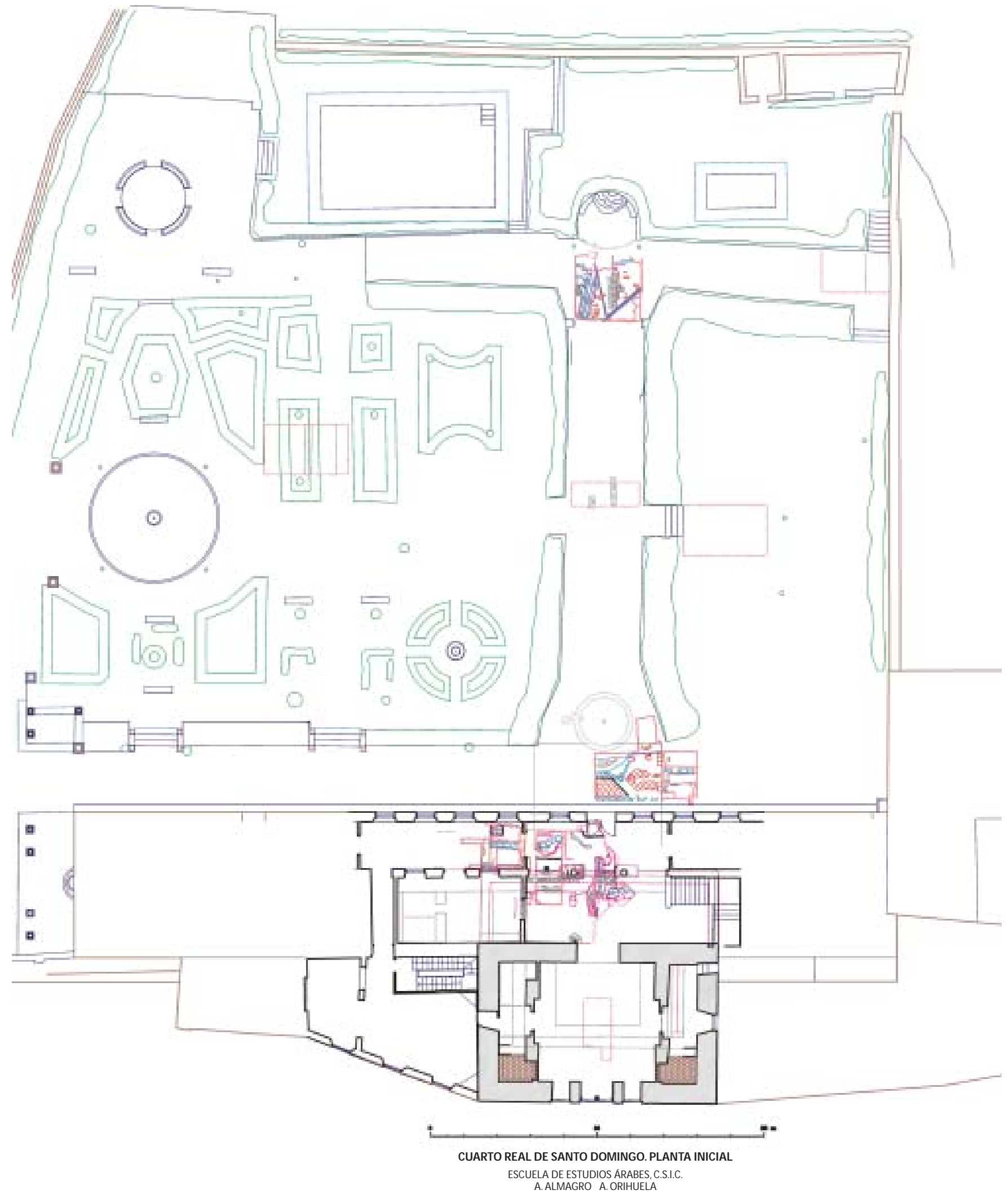

Fig. 3. Planta de las excavaciones en el jardín y en la qubba. 


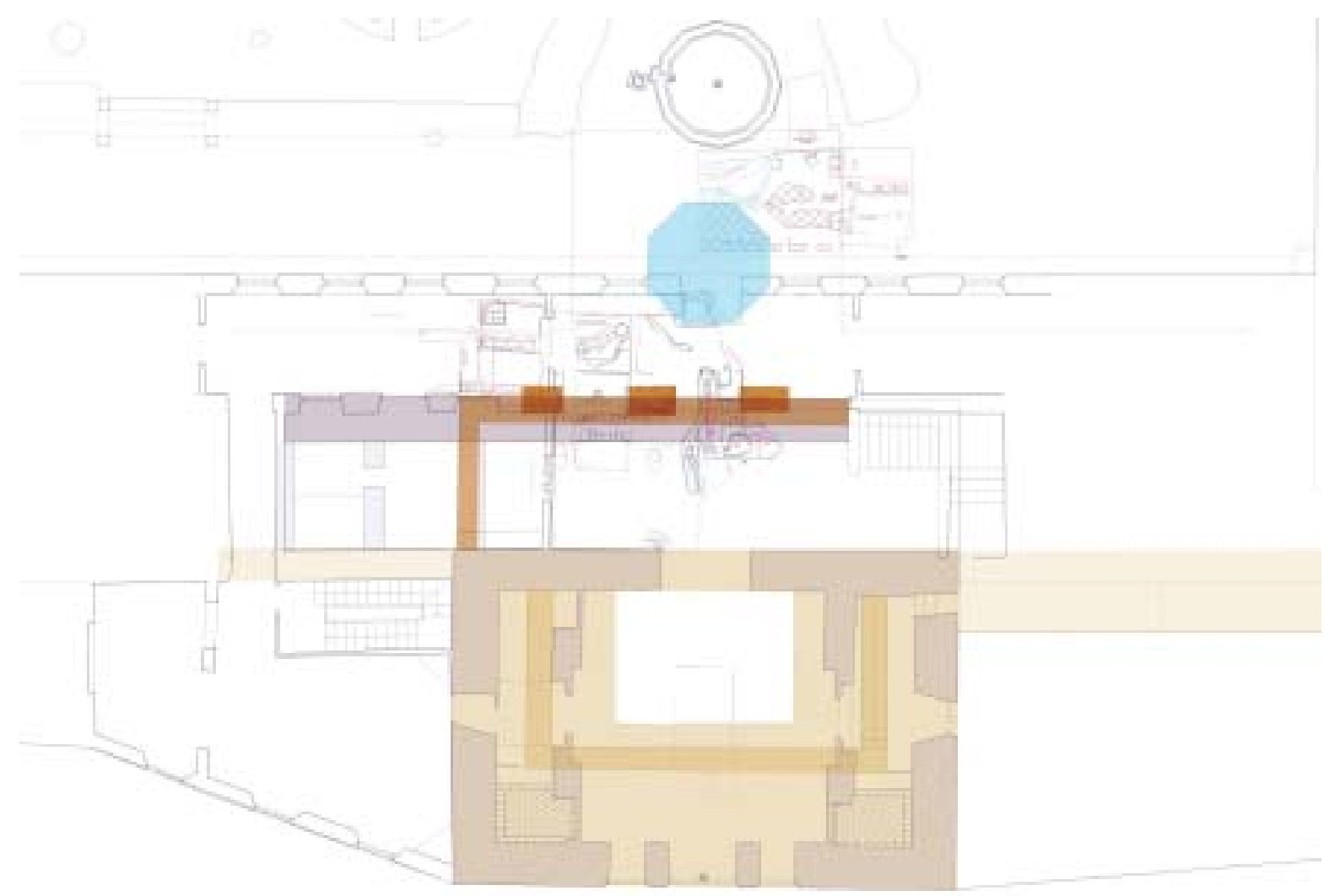

Fig. 4. Interpretación de las estructuras aparecidas en el subsuelo de la qubba y el vestíbulo.

métrico cuidadoso y preciso es un requi sito siempre indispensable para un adecuado proceso de restauración que difícilmente puede garantizar la sal vaguarda de los val ores patrimoniales sin el recurso a esta metodología de trabajo.

Estos trabajos de investigación no pueden reducirse exclusivamente a los estudios previos a la redacción del proyecto de restauración. La fase de obra se revela como un momento clave para ahondar en el conocimiento de un edificio pues es cuando en muchos casos pueden hacerse auténticas disecciones de la construcción. En el momento de redactar este artículo, se ha superado ya prácticamente la fase de demoliciones y eliminación de enlucidos modernos, por lo que no cabe esperar muchas más novedades. En general se han confirmado las hipótesis iniciales aunque obteniéndose más datos y más detalles. La dendrocronol ogía real izada a partir de muestras sacadas a las maderas de la armadura por la parte superior ha permitido avanzar provisional mente una fecha que abundaría en la antigüedad del edificio que se dataría en el tercer cuarto del siglo XIII. Quedan por perfilar fechas de intervenciones posteriores en la qubba que nos consientan dar cronología absoluta a las distintas fases constructivas detectadas.

Por presentar solo una muestra de lo que ha supuesto la investigación realizada antes y durante los trabajos de restauración, vamos a exponer el anál isis de tres zonas concretas. Una es la excavación bajo el nivel de suelo, realizada en la zona del jardín y del vestíbulo actual del edificio. La segunda es el análisis de las estructuras que transformaron el espacio interno de la sal a-qubba y sus espacios saté lites, que se ha culminado en las labores de recuperación de la disposición original. La tercera corresponde al análisis de enlucidos en el muro exterior de la qubba, tanto en el vestíbulo como en la linterna.

\section{Excavaciones en el subsuelo}

Las excavaciones del subsuelo han permitido identificar las estructuras del jardín, sus límites orientales y occidental así como localizar construcciones en el extremo norte, opuesto a la qubba, cuya correcta interpretación requiere ampliar la zona excavada (fig. 3). A unque el límite septentrional del jardín aún no ha podido fijarse con preci- 


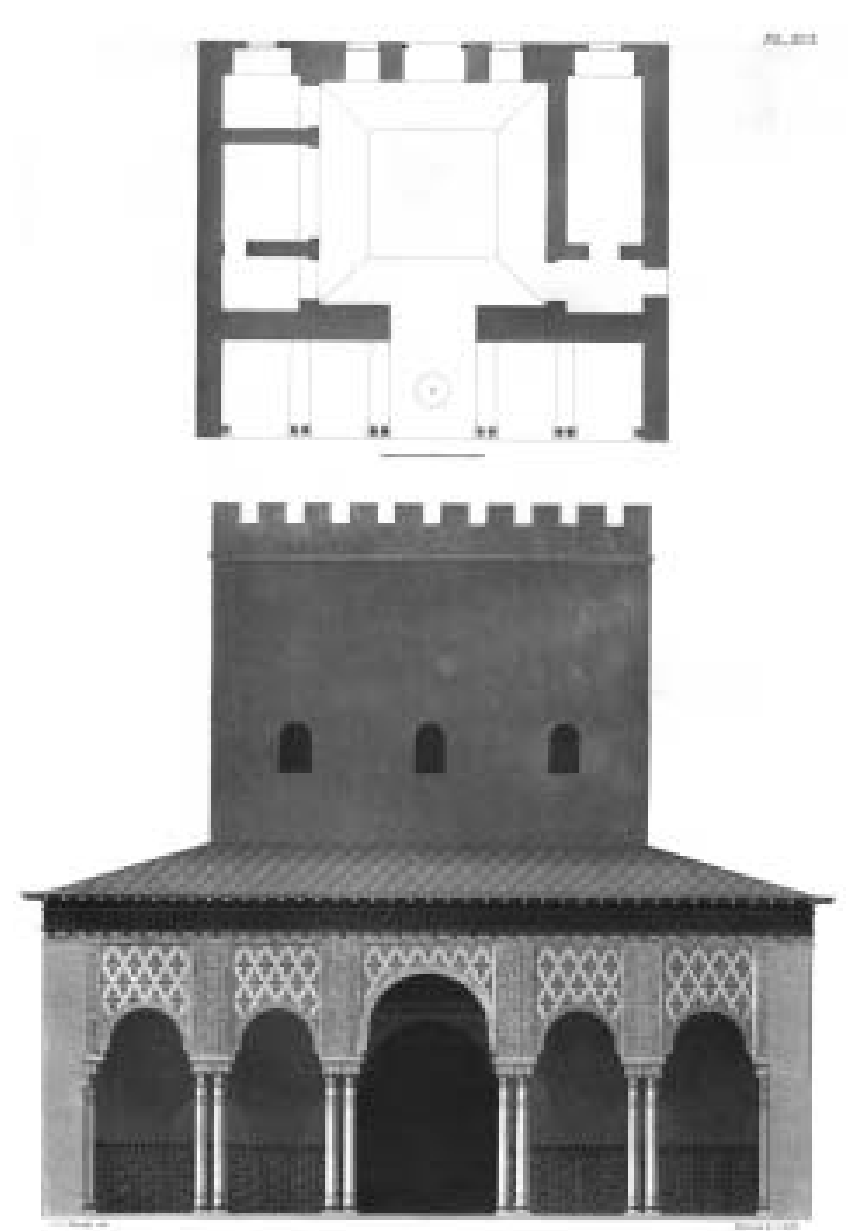

Fig. 9.Grabado de Murphy del Cuarto Real de Santo Domingo.

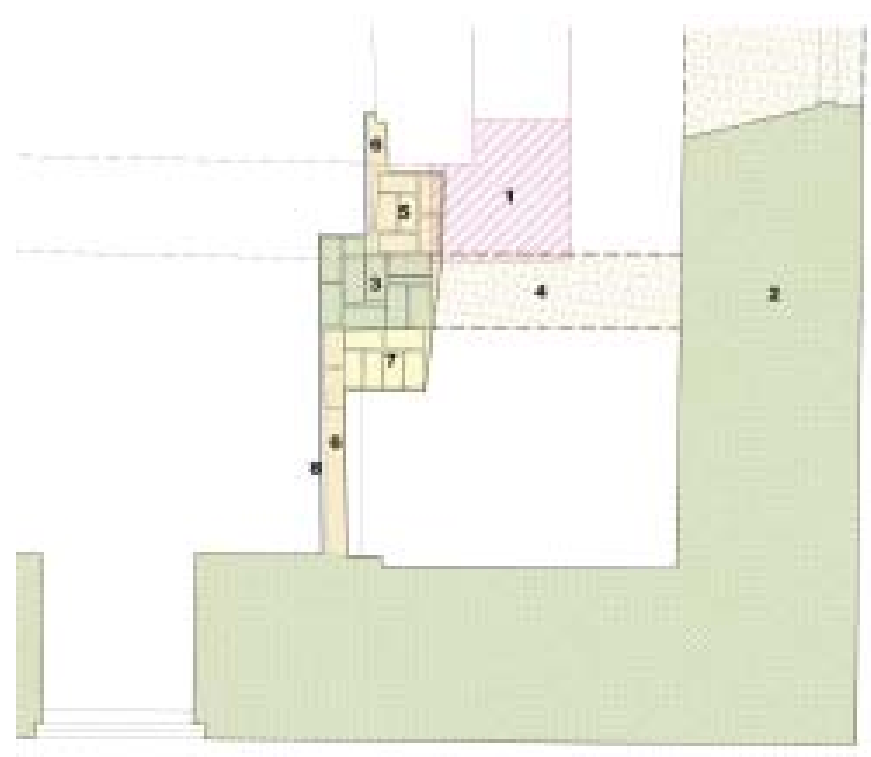

Fig. 5. Análisis de uno de los machones del interior de la qubba, con las distintas fábricas numeradas por orden cronológico: 1.- estructura anterior por debajo de nivel de suelo, 2.- muro de la torre, 3.- testa del muro divisorio de las alhanías, 4.muro de tapial divisorio desaparecido, 5.- primer refuerzo del pilar, 6.- muros de cierre de las alhanías, 7.- segundo refuerzo del pilar, 8.- aplacado y enlucido. sión, todo apunta a que las estructuras encontradas constituyeron, en los distintos períodos, el ementos de cierre y separación con el resto de la huerta que lo rodeaba. Se ha podido determinar que el jardín contó con un andén central y otros perimetrales, escasamente sobreelevados respecto al terreno de cultivo, que además apenas supera los $30 \mathrm{~cm}$. de potencia por encima del conglomerado natural conocido como "formación Alhambra".

En las inmediaciones de la qubba (fig. 4), por delante deella, la excavación ha permitido localizar entre otras cosas la al berca octogonal que existió frente a la qubba, los restos del andén y una serie de estructuras a nivel de cimientos cuya interpretación puede sintetizarse del siguiente modo: Existe un gran muro de tapia de hormigón de cal, que corre paral el o al frente de la qubba, unos cuatro metros por delante de la misma y que puede tratarse de una antigua estructura de contención de la terraza en que se asienta la huerta y el jardín, pues todo parece indicar que la muralla seguía una línea más al sur enrasada con el muro delantero de la qubba. Este gran muro bien puede corresponder a una fase anterior a la construcción de la propia qubba.

Sobre este muro se asentó otro más estrecho que se cierra con el extremo de la torre, determinando un espacio rectangular del que sólo se ha podido hasta ahora estudiar su parte oeste. EI muro de cierre lateral tuvo al zado sobre rasante según puede apreciarse de su entronque con la qubba, en donde el forro de ladrillo adosado al construir el edificio del siglo XIX también se adosa en su parte baja a los restos de aquél. En el frente norte de esta estructura no se puede saber qué al zado tuvo ni si es obra coetánea de la torre. Pudo ser una sal a cerrada, anterior a aquélla, o simplemente la cimentación corrida de un pórtico, o incluso haber pasado por ambas fases. Sí sirvió de asiento a la cimentación de un pórtico de cinco vanos que fue sin duda el que se representa y cita en grabados y textos del siglo XIX, que quizás fuera refacción de otro anterior. En todo caso parece demostrarse que en este mismo emplazamiento existieron estructuras anteriores a la qubba que actualmente conocemos, pues también en su interior han aparecido restos de muros de lo que podría haber sido una torre o qubba más antigua de dimensiones más reducidas, que quedó envuelta por la construcción actual como sucedió en la torre de Comares de la Alhambra.

\section{Análisis de las estructuras internas}

Especial interés para la identificación de la disposición primitiva del espacio interior de la construcción se presentaba en el análisis de los elementos que cerraban las al hanías lateral es y que habían transformado a la qubba en 
un espacio de planta cuadrada cerrado en su perímetro, con tres ventanas en el lado sur y el arco de entrada en el norte. Un análisis de la planta publicada por Murphy (MURPHY, 1987: pl. XCl) y una revisión superficial de los enlucidos que presentaban diversas fisuras ya nos había permitido plantear la hipótesis de una disposición muy distinta a la que había llegado hasta nosotros (fig. 9). El picado de los enlucidos por la zona interna de los espacios laterales vino a confirmar la existencia de distintas transformaciones con agregado de el ementos estructurales. EI levantamiento de las solerías modernas confirmó la hipótesis y apuntó la existencia de estructuras, seguramente anteriores, por debajo de la rasante de suelo como ya hemos apuntado. Por último, la demolición de las estructuras agregadas que habían producido una transformación espacial importante, ha confirmado las teorías y aportado detalles adicionales sobre su cronol ogía relativa y sobre las formas constructivas originales.

La figura 5 nos muestra con claridad la yuxtaposición de fábricas que se repite en cada uno los machones que constituían las testas de los muros que separaban los espacios laterales, todos ellos originalmente con aberturas hacia el espacio central de la qubba. La disposición primitiva era a base de muros transversales a los muros exteriores de la torre, construidos en tapia como aquéllos, pero con sus testas hacia el espacio central realizadas con fábrica de ladrillo enjarjada con el tapial, solución semejante a la que se aprecia también en las jambas del arco de entrada a la qubba. Precisamente esta disposición había provocado que al demolerse las partes de tapia y rellenarse los retalles o enjarjes con nuevo ladrillo, quedara en la parte posterior una cara vista y lisa de ladriIlo que hacía pensar que se tratara de pilares exentos y no de restos de los muros. Esta fal sa imagen se producía porque al estar las caras lateral es de los machones ocultas por otros pilares adosados, no resultaban visibles dichos enjarjes, dando la apariencia de ser pilares de fábrica homogé nea. La existencia de los muros de separación se había evidenciado por distintas huellas dejadas tras su demolición, tanto a nivel de sus arranques, donde en al gún lugar habían quedado ladrillos dispuestos para asiento de la tapia, como por marcas dejadas en el muro exterior también de tapia, a pesar de que, como es habitual, los muros hechos con esta técnica no se suelen trabar entre sí. Mayor evidencia aportó el descubrimiento de un zócal o pintado de época nazarí sobre el muro exterior de la alhanía oriental que presentaba la cenefa lateral de remate precisamente donde debía entestar el muro desaparecido. 0 tros restos de esa misma pintura han aparecido en los laterales de los machones o testas de ladrillo al demoler las estructuras adosadas.

La demolición de los muros de separación de los distintos espacios laterales de la qubba obedecía al deseo de aprovechar éstos como espacios unificados entre sí, pero separados del principal. No sabemos con certeza en que momento se realiza esa reforma, pero a juzgar por el grabado de M urphy, que dibuja una al hanía aún abierta y otra cerrada, debió de culminarse tras la Desamortización y antes de que se tomen las primeras fotografías del interior de la qubba a comienzos del siglo XX en las que aparecen las al hanías cerradas. Seguramente se haría al incorporar la qubba a la vivienda construida en torno a ella en la segunda mitad del siglo XIX. Al el iminarse los muros de tapia y dejar las testas de ladrillo exentas como si fueran pilares, debido a su fragilidad y esbeltez, la estructura del edificio se debió resentir y empezaron a realizarse refuerzos sucesivos, nunca en el sentido de recuperar la disposición primitiva sino de abundar en la reforma.

La primera intervención consistió en levantar pilares adosados por el lado de la al hanía central como el ementos de refuerzo. Estos pilares parecen ser contemporáneos a los muros de cierre de todas las al hanías, que parecen haberse levantado simultáneamente. Estos pilares taparon parte del enlucido nazarí incluyendo restos de pinturas que han aparecido al procederse a su demolición. Los dos más meridionales se asentaron sobre los restos del muro de la estructura más antigua, quizás una torre o qubba anterior, ya mencionado. Los pilares atraviesan los al farjes con que al comienzo del período cristiano, se dividió la altura de las al hanías, formando sendas tribunas. Para ello se desmontó la tablazón pero no las viguetas. En una fase posterior se construyen otros cuatro pilares adosados a los testeros de los antiguos muros por el lado opuesto. Se apreciaba con claridad que estos nuevos el ementos se adosaban tanto al muro antiguo como al muro moderno de cierre de las saletas laterales y rompen los pavimentos antiguos conservados en los dos cuartos o al hacenas meridionales. En el cuarto 0 alhacena del ángulo nordeste, el pilar se extendió a todo al ancho del primitivo hueco de acceso a la misma, forrando incluso con la misma fábrica parte del muro norte de la torre.

A una fase posterior corresponde el enlucido y acabado de los muros de cierre de los espacios lateral es por la cara que da al interior de la qubba. Se colocó un zócalo de mármol en grandes placas de al rededor de $1 \mathrm{~m}$. de altura y el resto de los paños se enlucieron con yeso decorándose con trama de sebka incisa como en el resto de las paredes de la qubba. En los paños que ciegan las al hanías centrales 


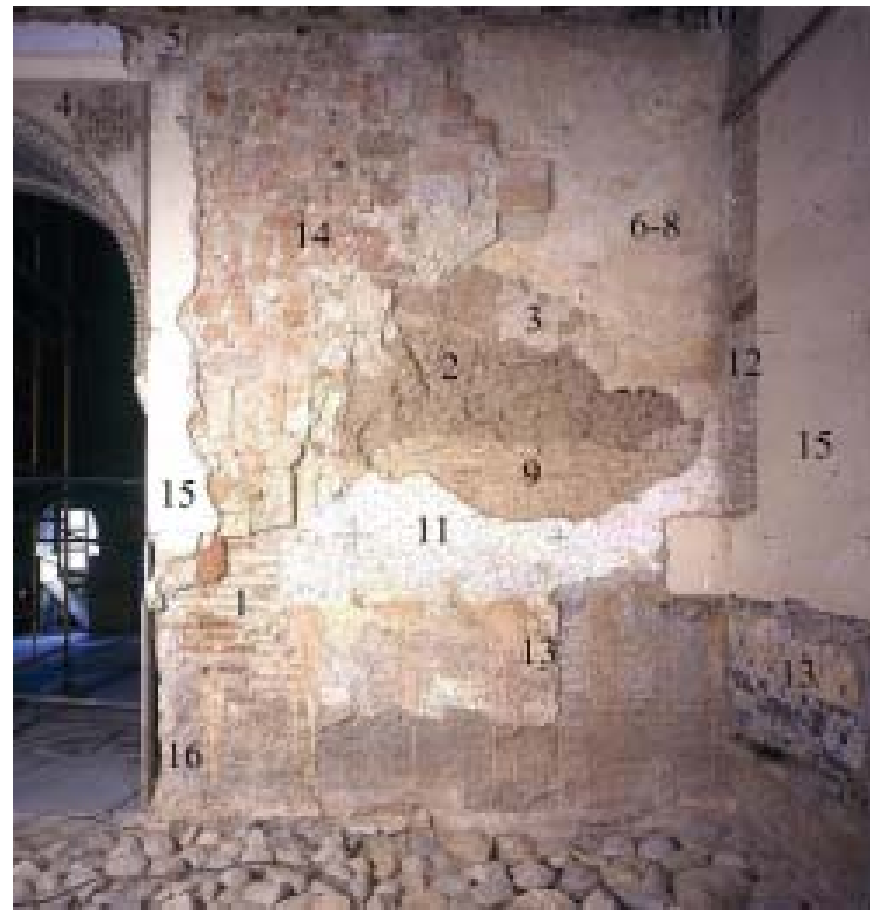

Fig. 6. Interpretación de los enlucidos en el paramento del vestíbulo.

la decoración era geométrica en forma parecida a una esvástica y con pequeñas piezas clavadas. Lo peor de esta intervención, es que para ajustar las placas de mármol al plano de los al icatados se recortaron los al izares y el alicatado con estrellas de ocho que formaban los peldaños de entrada a los dos cuartos-al hacenas del lado sur en una operación que hay que juzgar cuando menos de bárbara al haberse realizado en fecha muy reciente, seguramente en la década de 1930.

Otro de los hallazgos de interés producido al reabrir los huecos clausurados fue detectar en las jambas de los vanos de estas habitaciones improntas que denotan que tuvieron marcos de carpintería, algo que ya habíamos supuesto al redactar el proyecto de restauración.

\section{Análisis estratigráfico de enlucidos}

Uno de los lugares en que se puedo analizar con bastante claridad la estratigrafía muraria fue en el paramento situado al lado derecho del arco de ingreso, paramento que correspondió al fondo del pórtico hoy desaparecido. Tras un picado sel ectivo de los enlucidos se pudieron visualizar las siguientes fases, identificables en la fig. 6 : I.- Tapial con su acabado liso característico con acumulación de cal (3). Este tapial presenta zonas descarnadas (2). La jamba del arco de la puerta está real izada con fábrica de ladrillo como suel e ser habitual (1).

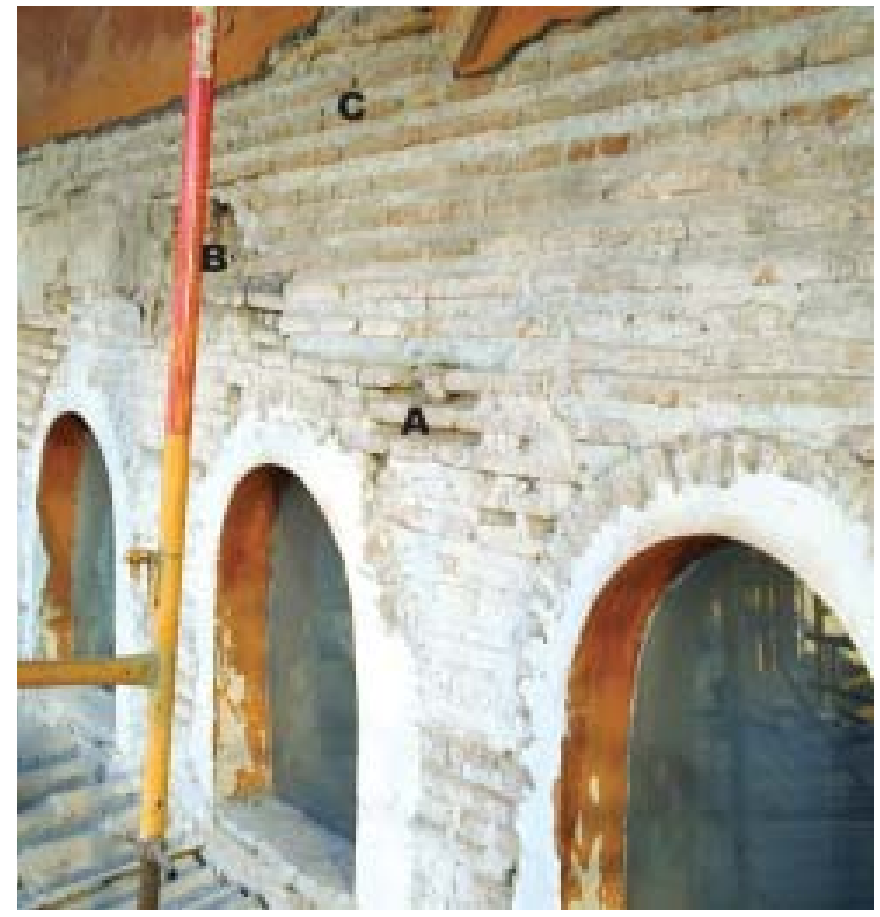

Fig. 7. Muro de la linterna de la qubba con sus distintas fábricas y fases. A.- fábrica de ladrillo nazarí, B.- restos del cajón de tapia nazarí, C.- Fabrica de ladrillo de la refacción moderna.

II.- Capa de yeso de unos $8 \mathrm{~mm}$., seguramente el enlucido original. Presenta la superficie apiconada para mejorar el agarre de la capa posterior (6).

III.- Capa de yeso de $6 \mathrm{~mm}$. también con picotazos (7).

IV.- Capa de yeso de $3 \mathrm{~mm}$. con picotazos muy finos (8).

V.- Capa de mortero de cal de grosor variable entre 10-20 $\mathrm{mm}$. con picotazos (11). Cubre los enlucidos anteriores y la fábrica de ladrillo de la parte baja que parece ser un recalce de reparación del tapial (9), pues no se aprecia sobre ella ningún resto de los enlucidos antes mencionados. Esta reparación tiene ladrillos de distintos tamaños aunque predominan los de $30.5 \times 15 \times 3.5 \mathrm{~cm}$. El enlucido de cal acomete contra la tocadura de un resto de alfarje del que se conservan dos vigas junto al muro occidental (10), lo que permite suponer la contemporaneidad de enlucido y alfarje. Este enlucido de cal es anterior al muro lateral oeste que se adosa a él (12), corriendo por detrás del enteste. Tiene encima una capa de pintura a la cal de color rosado y varias de color blanco.

VI.- Capa de yeso de 7+3 mm. que solo aparece en la parte baja, sobre el mortero de cal, con pinturas al temple imitando alicatados (13). Q uedó cubierta por el aplacado de mármol (16), y se extiende por el muro lateral oeste (12).

VII.- Capas de yeso de aspecto terroso de $8+3+5 \mathrm{~mm}$., con ladrillos a bofetón y baldosas de fabricación mecánica que recrece el paramento para regularizarlo (14), provocando la 


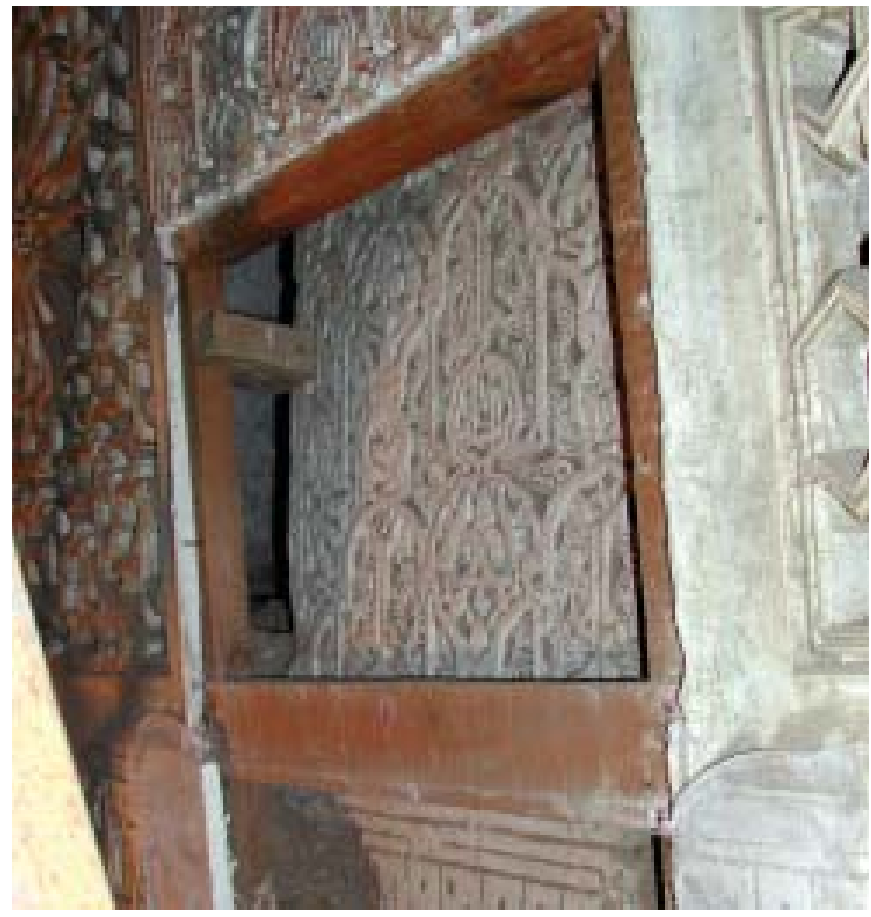

Fig. 8. La decoración original del paramento oeste con el recubrimiento de placas de escayola.

necesidad de hacer un biselado o chaflán al llegar al arco para recuperar el nivel original. Está en relación con el aplacado de mármol, aunque puede ser contemporáneo del enlucido con pinturas que aparece debajo del aplacado pues ambos están sobre el mortero de cal. Se extiende al muro lateral.

VIII.- Capa de enfoscado de cemento de $8+4 \mathrm{~mm}$. (15), contemporáneo al aplacado de mármol que cubría todo el zócalo, aunque en la foto sólo se aprecia en la jamba del arco de ingreso a la qubba (16).

Al picar las dos escuadras superiores del alfiz del arco de ingreso a la qubba para comprobar el enlace del enlucido original con la yesería del arco (4), se confirmó su relación en ambos lados, apareciendo los empotramientos de las dos gorroneras de mármol blanco castreadas a haces del muro (5). Las gorroneras no parecen ser coetáneas de la yesería pues la capa de yeso del arco se ve rota para introducir las piezas en el muro, que se reciben con un yeso más basto y con ripios de cantos rodados planos. Existe un enlucido de yeso muy fino $(1 \mathrm{~mm}$.) que recubre el yeso con que se recibieron las gorroneras y el enlucido anterior, hasta morir en el vivo del recercado del arco. Esta capa de enlucido, aunque no tiene continuidad, podría ser la misma que la (7) 0 la (8) Correspondientes a las fases III y IV.

Este paramento refleja con claridad la historia del edificio. Las fases I a IV son medievales. Las dos últimas pueden corresponder a acabados 0 a reparaciones. Es lógi- co pensar que al menos la última sea una reparación, normal en un edificio con más de dos siglos de vida medieval. La fase $V$ corresponde a la utilización del edificio en época moderna. La dendrocronología apunta una intervención importante en el siglo X VIII, por lo que cabe asignar esta fase a tal fecha. La fase VI, que incluye ya el muro lateral oeste perteneciente al edificio contemporáneo es sin duda el primer momento de éste. La decoración de alicatado fingido es característica. La fase VII pudiera ser coetánea de la VIII, al tratarse de una regularización del paramento que en la zona baja incluyó un aplacado de mármol sujeto con grapas y ligeramente separado de la base del muro.

Otros puntos de interés en donde el anál isis de paramentos ha permitido establecer cronologías relativas de determinadas tranfformaciones, han sido los exteriores del cuerpo de la linterna. En el frente occidental, el muro de ésta presentaba una serie de al teraciones cuya cl arificación se ha logrado al eliminar gran parte de los enlucidos de cemento que presentaba. Tanto en el lado oriental como en el occidental, estos muros de la linterna cruzan sobre los vanos de las al hanías laterales de la sala interior, apoyándose en realidad sobre dinteles y cargaderos de madera ya que los arcos, como suele ser habitual en lo nazarí, no son portantes sino simplemente ornamentales. A demás, en las alhanías centrales se da la particularidad de que estos muros se apoyaban incluso sobre parte del alfarje que cubría a aquéllas, pues sus viguetas se dispusieron desde el muro de la linterna hasta el muro exterior de la torre.

Los muros son de tapia por encima de los cargaderos y hasta la altura de las ventanas. Las jambas, arcos y enjutas de éstas son de ladrillo corriendo un par de hiladas por encima de las claves. Más arriba continuaba un cajón de tapia con las esquinas de ladrillo y hay indicios de una o dos hiladas de ladrillo que servirían de apoyo al al ero.

La solución con que se cubre el vano de las alhanías, que desde el punto de vista constructivo resulta sumamente inapropiada, produjo en el lado oriental y en una fecha que desconocemos, un vuelco del muro de la linterna, seguramente por fallo del alfarje que acabamos de mencionar. Esto provocó un acusado desplome hacia el exterior, que pese a todo apenas afectó a la armadura de la cubierta, estabilizada por su grueso estribo. Estos daños fueron reparados desapareciendo todo vestigio del alfarje en este lado y colocándose cargaderos nuevos de madera en la parte externa del muro que era la que cargaba sobre el forjado. Para paliar el vuelco del muro, se desmochó este por encima de las claves de los arquillos de las ventanas, reconstruyéndose con fábrica de ladrillo y mortero de buena cal (fig. 7). De este modo se aprecia una parte del muro, la 


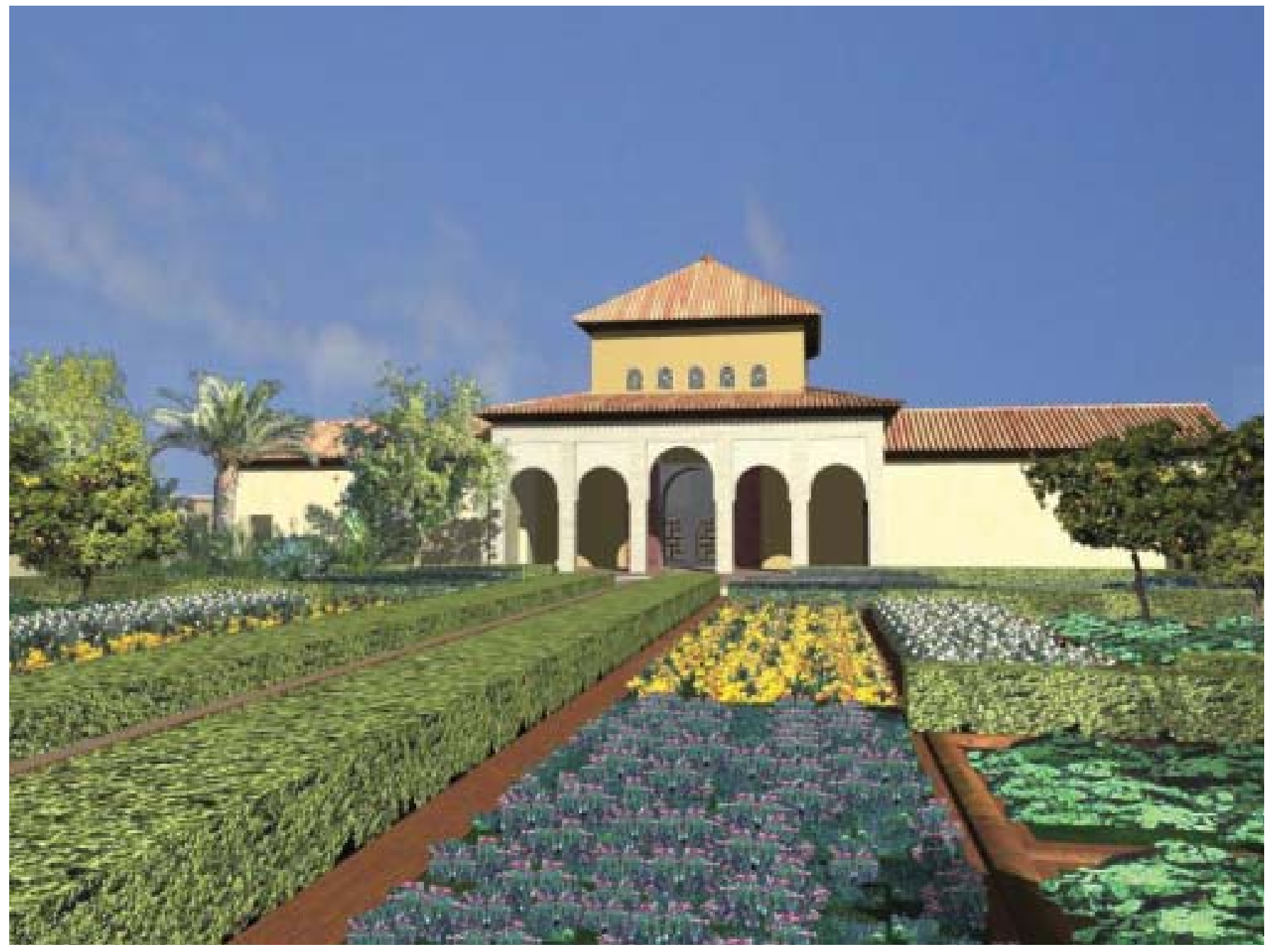

Fig. 10. Propuesta para la recuperación del pórtico y el jardín del Cuarto Real de Santo Domingo.

inferior, con fuerte vuelco, mientras la superior está perfectamente vertical. En el interior de la sala, el muro mantuvo el vuel co perdiendo la decoración de la parte superior, sustituida por un regruesado regularizador. Toda esta zona fue recubierta en fecha muy reciente, seguramente en la década de los años 1930, por una decoración de placas de escayola clavadas sobre unos bastidores de madera que reproducen la decoración existente debajo y la desaparecida de la parte superior (fig. 8).

La datación del alero actual que nos facilita la dendrocronol ogía apunta a una refacción del mismo en el siglo XVIII. Es muy probable que con tal motivo se sustituyera el primitivo nazarí, que sería inclinado, por el actual horizontal. Ello obligó a recrecer el muro con varias hiladas de ladrillo en todos los lados de la linterna, que tienen factura y mortero semejantes a las de la reconstrucción del lado occidental. El mortero de esta fábrica es muy distinto del nazarí que tiene un al to contenido en tierra roja. Por tanto, se puede suponer que en el siglo XVIII se realizaron obras de envergadura en el edificio que atajaron daños importantes. Quizás de este mismo momento sean los careados con fábrica de ladrillo y enlucido con mortero de cal de la fachada de este mismo lado occidental que presenta una ornamentación esgrafiada que puede ser de esa fecha.

Con posterioridad se han real izado enfoscados de distinto tipo, los más recientes con mortero de cemento que recubren las rozas en que se al ojaron los tirantes metálicos colocados en la década de los años 1930, rozas que a su vez están rellenas de yeso envolviendo los tirantes. La última capa la forma un mortero de cal parcheando fallos y una pintura roja de la intervención realizada por el Ayuntamiento en 1992.

\section{Propuesta de intervención y recuperación de la qubba}

Lo que hoy sabemos del Cuarto R eal a través de las excavaciones y análi sis arqueológicos real izados y de los graba- 
dos y descripciones anteriores a la edificación del edificio moderno es que la qubba tuvo delante un pórtico, quizás rehecho en época post-medieval, que éste contaba con cinco arcos sobre columnas pareadas y que estaba decorado con yeserías (fig. 9). Por otro lado, sabemos que la qubba ocupaba el frente de un jardín con al berca, andenes y tapias de cerramiento cuya ubicación se ha localizado, y que se encontraba a su vez rodeado de huertas. Un modelo muy semejante al del Generalife.

La propuesta de restauración redactada desde la Escuela de Estudios Árabes consiste en recuperar los valores fundamentales de este conjunto, único de este tipo en el que aún es posible hacerlo no solo en Granada sino en todo al-A ndalus (la destrucción de los entornos del Al cázar Genil y de la Buhayra de Sevilla los hacen irrecuperables). Se pretende restaurar la qubba recuperando su primitiva estructura y disposición interna, y se planteaba rehacer un pórtico sin intención de copiar el original, del que por otro lado no contamos con la suficiente información, volviendo a disponer el jardín con sus andenes, tapias y alberca siguiendo su forma primitiva (fig. 10). Pese a que el pórtico, cuya construcción proponemos, no podría en ningún momento confundirse con uno original nazarí, se ha acusado a esta propuesta de restauración supuestamente estilística. Parece como si a la ignorancia de quienes hacen estas afirmaciones, que parecen desconocer las formas y disposiciones constructivas de la arquitectura nazarí, se uniera la no aceptación como moderno de todo aquello que no suponga un contraste radical con lo antiguo, ya sea por el empleo de materiales disonantes, ya por el uso de formas extremadamente distintas, ya por la imposición de volúmenes desproporcionados. $\mathrm{Ni}$ el ladrillo ha dejado de ser un material moderno, ni el arco ha dejado de ser una forma actual. Y constructivamente, los arcos que hemos diseñado jamás se hubieran realizado así en época nazarí.

La al ternativa a esta propuesta que se pretende imponer desde la Administración responsable de la tutela del Patrimonio es la conservación del edificio moderno. Se aducen razones de preservación de un elemento histórico. Desde luego cual quier evento, por insignificante o negativo que sea, es histórico, pero no todos los hechos históricos tienen la misma relevancia ni pueden merecer el mismo juicio ni tratamiento. El edificio moderno es arquitectónicamente malo y constructivamente muy deficiente y en ningún momento planteó con sensibilidad una integración de lo preexistente. Su aspecto actual obedece a una reforma de los años 30 del pasado siglo sin ningún interés esté tico y sin que pueda decirse que responde a ningún estilo ni represente ninguna tendencia arquitectónica. Su ade- cuación a un uso público exigirá una cuantiosa inversión y obligará a su casi completa reconstrucción, haciéndole perder cualquier val or histórico, si es que lo tiene. Se convertirá en un edificio moderno según el gusto de quien lo rehabilita y supondrá incidir y perpetuar lo que ya supuso su primitiva construcción: la destrucción de los valores más interesantes del monumento nazarí como una consecuencia más de la Desamortización que tantos estragos produjo en nuestro Patrimonio $\mathrm{H}$ istórico. $\mathrm{H}$ asta entonces, la qubba y su jardín se habían conservado casi intactos, al menos en lo esencial. Con su paso a manos privadas se destruyó el pórtico, se terraplenó la al berca y el jardín y desapareció la interrelación entre el jardín y el salón a través del pórtico y la al berca, val or fundamental de este conjunto, al construirse una vivienda de escasa calidad que sólo aprovechó la qubba como un el emento exótico sin nada que ver con su primitivo uso.

Pensamos que qui enes plantean esta solución carecen de una idea clara respecto a los val ores del Cuarto Real de Santo Domingo y que por tanto se está jugando con él sin plena conciencia del al cance y resultados finales a que conducirán las propuestas que se barajan. Solo por esto se entiende que este conjunto no sea ya lo que debía ser desde hace muchos años: un monumento excepcional digno de visitarse, un lugar sin par en que desarrollar actos protocolarios, un ejemplo único de jardín hispanomusulmán, un parque público en medio de la ciudad en que bajo la forma de una huerta se enseñara el uso del agua y de los cultivos, de las plantas y las formas de hacer bello lo utilitario... de Io que fue la agricultura en al-Andal us y en G ranada. Todo ello por mucho menos de lo que costaría poner en funcionamiento el edificio moderno, ahorrando unos fondos que bien merecen muchos otros monumentos de la ciudad en que podrían ubicarse los usos a los que supuestamente pretende dedicarse el Cuarto R eal.

\section{EL PATIO DEL CRUCERO DEL ALCÁZAR DE SEVILLA}

El Alcázar de Sevilla es el más viejo palacio real europeo que mantiene tal función, pues desde el siglo XI hasta el día de hoy ha sido de forma ininterrumpida residencia de los monarcas Abbadíes, Almorávides, Almohades, Castellanos, Augsburgos y B orbones. Conserva aún estructuras que pueden datarse desde el siglo XI hasta la actualidad, que se han ido superponiendo y agregando en un proceso histórico siempre complejo y en muchas ocasiones de difícil lectura.

En la génesis y desarrollo de este conjunto se aprecian dos modos o sistemas distintos de conformación del complejo arquitectónico. El sistema que podemos denominar 

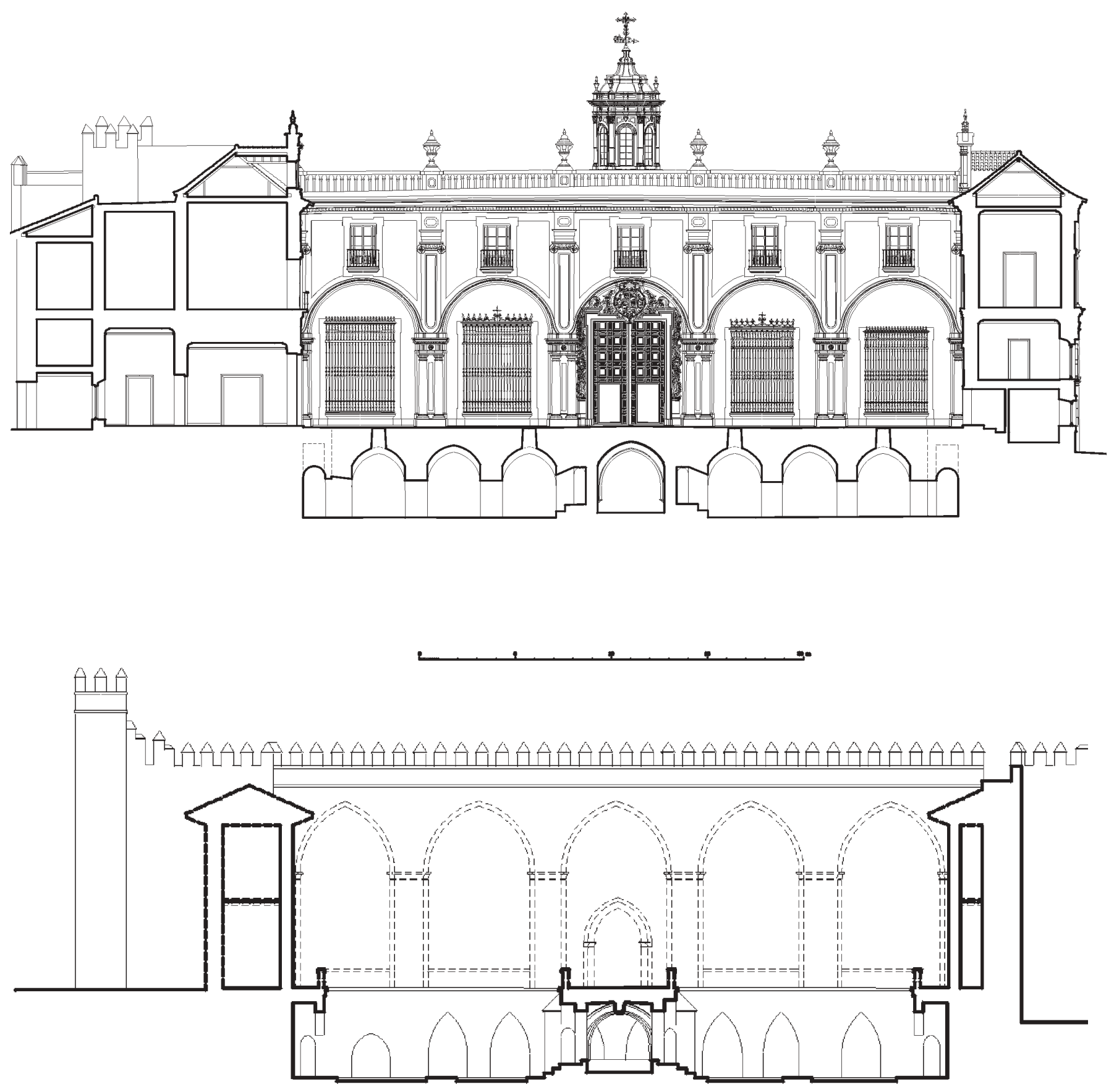
islámico es un proceso de yuxtaposición. El pal acio islámico se suele caracterizar por estar formado y haberse generado mediante añadidos que provocan un crecimiento en extensión. El pal acio se mantiene a nivel del suelo. Se constituye mediante una agregación de unidades, construidas contemporáneamente 0 en momentos distintos, que se mantienen muchas veces autónomas y que son usadas según el particular deseo del morador del palacio. El sistema cristiano puede definirse como un sistema de sobreelevación. Las nuevas unidades se generan construyendo en plantas superiores y dotando a los espacios de uso y significación concretos.

La presencia de estos dos sistemas, continuados en el tiempo, ha provocado una realidad compleja de difícil análisis, sobre todo por otra serie de circunstancias agregadas. En primer lugar, al tratarse de edificios en uso constante, no es fácil la realización de investigaciones, sobre todo en las estructuras murarias que se encuentran, como es lógico, enmascaradas por revocos y enlucidos, que en general están bien entretenidos. Por otro lado, este singular conjunto carecía, hasta muy recientemente, de una documentación planimétrica adecuada y precisa.

A fortunadamente, acaba de publicarse el primer trabajo de documentación planimétrica de este conjunto (AlMAgRo, 2000). El origen de este trabaj o fueron una serie de encargos realizados por el Patronato del Real Alcázar a la Escuela de Estudios Árabes del Consejo Superior de Investigaciones Científicas y plasmados en los correspondientes Convenios de colaboración científica (fig. 11). De este modo se ha podido aprovechar la experiencia en este tipo de trabajos del personal investigador y auxiliar de la Escuela, así como los equipos e instrumentos técnicos con que cuenta.

Previamente y por cuenta de la Gerencia M unicipal de U rbanismo del Ayuntamiento de Sevilla, el Patronato había logrado disponer de una planta del conjunto medida mediante procedimientos topográficos que incluían la materialización de una red de estaciones de observación. También desde la Escuel a de Estudios Á rabes se habían ido real izando al gunos trabajos de documentación, en particular la planimetría de las cubiertas de toda el área comprendida entre la Catedral y el Alcázar por medio de fotogrametría aérea.

Es indudable que el disponer de esta información constituye la base fundamental para seguir profundizando en el conocimiento de un conjunto tan importante e interesante como es el Alcázar de Sevilla. Además, tampoco puede menospreciarse la cuantiosa información adquirida en el transcurso de la medición y restitución, de la que sólo una parte puede quedar plasmada en los dibujos. Siempre hemos sostenido que el levantamiento arquitectónico debe entenderse como una forma de análisis y aproximación al conocimiento de los edificios que en ningún modo puede ser sustituido por otro tipo de investigación. La información que puede y debería generarse siempre durante el proceso de medición y dibujo, que por necesidad tiene que corresponder a un análisis exhaustivo de la propia materialidad de las estructuras arquitectónicas, es obviamente muy superior a la que luego puede quedar registrada en los dibujos finales.

Consecuencia de toda esta información es una serie de trabajos que hemos venido desarrollando de forma simultánea y con posterioridad a los del levantamiento gráfico y cuyo objetivo es profundizar en el conocimiento histórico y artístico de este conjunto palatino (A LMAGRo, 1999). Ya desde antes de acometer el levantamiento, nos habían Ilamado la atención distintas partes de conjunto por diversos motivos. Entre otros y de un modo especial después de medirlo y dibujarlo, hemos centrado nuestra atención en el denominado Patio del Crucero, en el que se adivinan transformaciones sucesivas desde su primitiva construcción, seguramente islámica, hastallegar a su estado actual de fisonomía barroca, pero encerrando el ementos góticos posiblemente de época de Alfonso $X$ el Sabio. Lo que más sorprende de esta parte del al cázar es la transformación topográfica sufrida y la metamorfosis que fue produciéndose a lo largo de los siglos que dio origen a soluciones arquitectónicas de una enorme originalidad que han quedado final mente enmascaradas después de las intervenciones del siglo X VIII. El levantamiento planimétrico en este caso, nos ha permitido disponer de unos medios de análisis e investigación indispensables para acometer el estudio de este conjunto, que ha sido objeto de una primera publicación específica y sobre el que hemos seguido trabajando mediante la recreación virtual de las distintas etapas de su existencia.

El palacio, primero islámico y luego cristiano, que se articula en torno al Ilamado Patio del Crucero, fue ya objeto de atención por parte de diversos investigadores, quienes trataron de describirlo literariamente aunque en general sin llegar a analizar con detenimiento su estructura y sobre todo, sin establecer con precisión una planta siquiera hipotética. Aún cuando nuestro estudio ha pretendido abordar el tema con mayor detalle y profundidad, hemos de reconocer las limitaciones que impone su situación actual ya que fue radicalmente trasformado tras el terremoto de Lisboa de 1755, lo que impide conocer muchos de sus detalles que se conservan bajo las tierras del jardín hoy plantado más de cuatro metros por encima de su nivel original. Por esta razón se debe enten- 


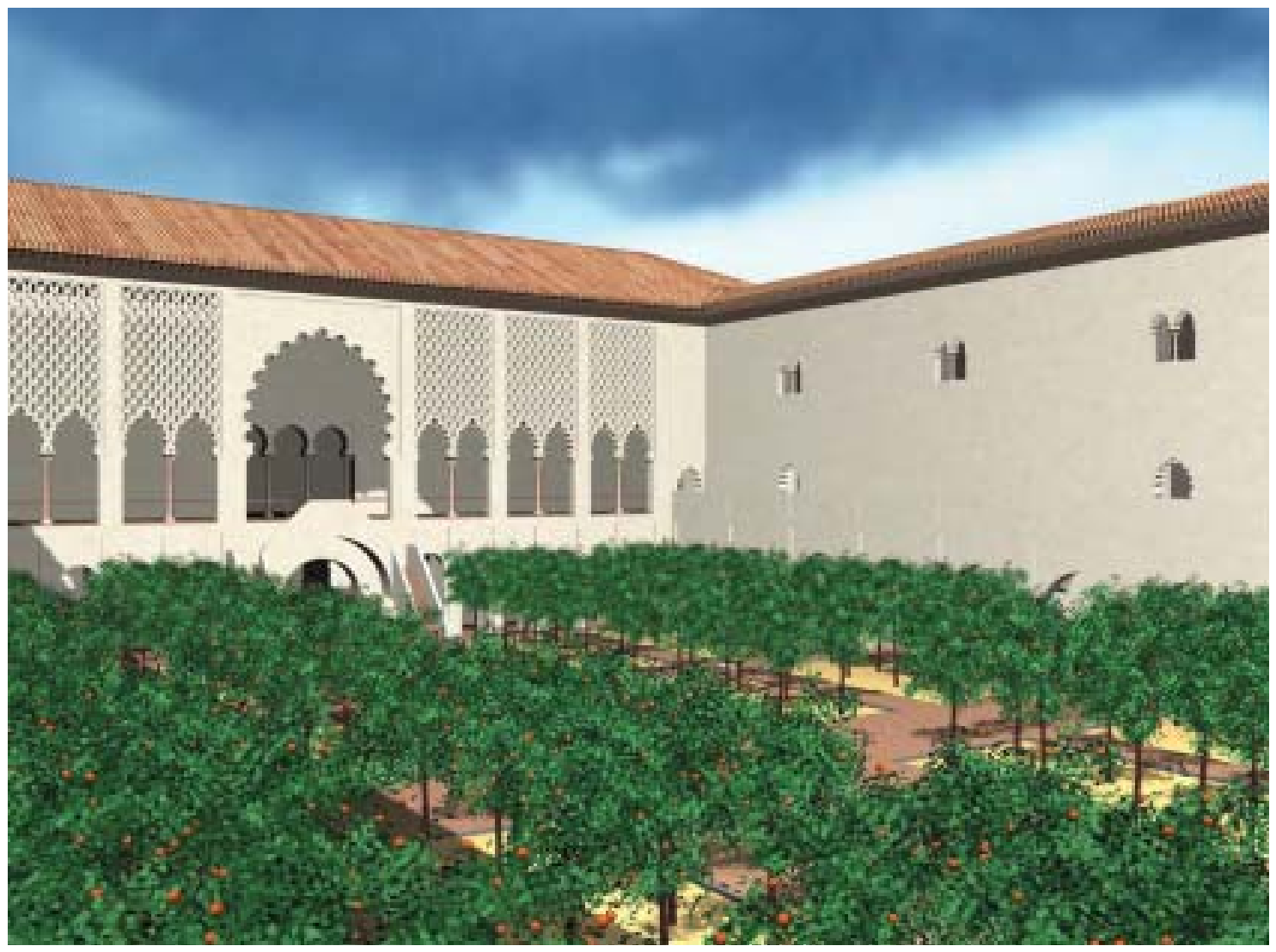

Fig. 14. Hipótesis del patio en época islámica.

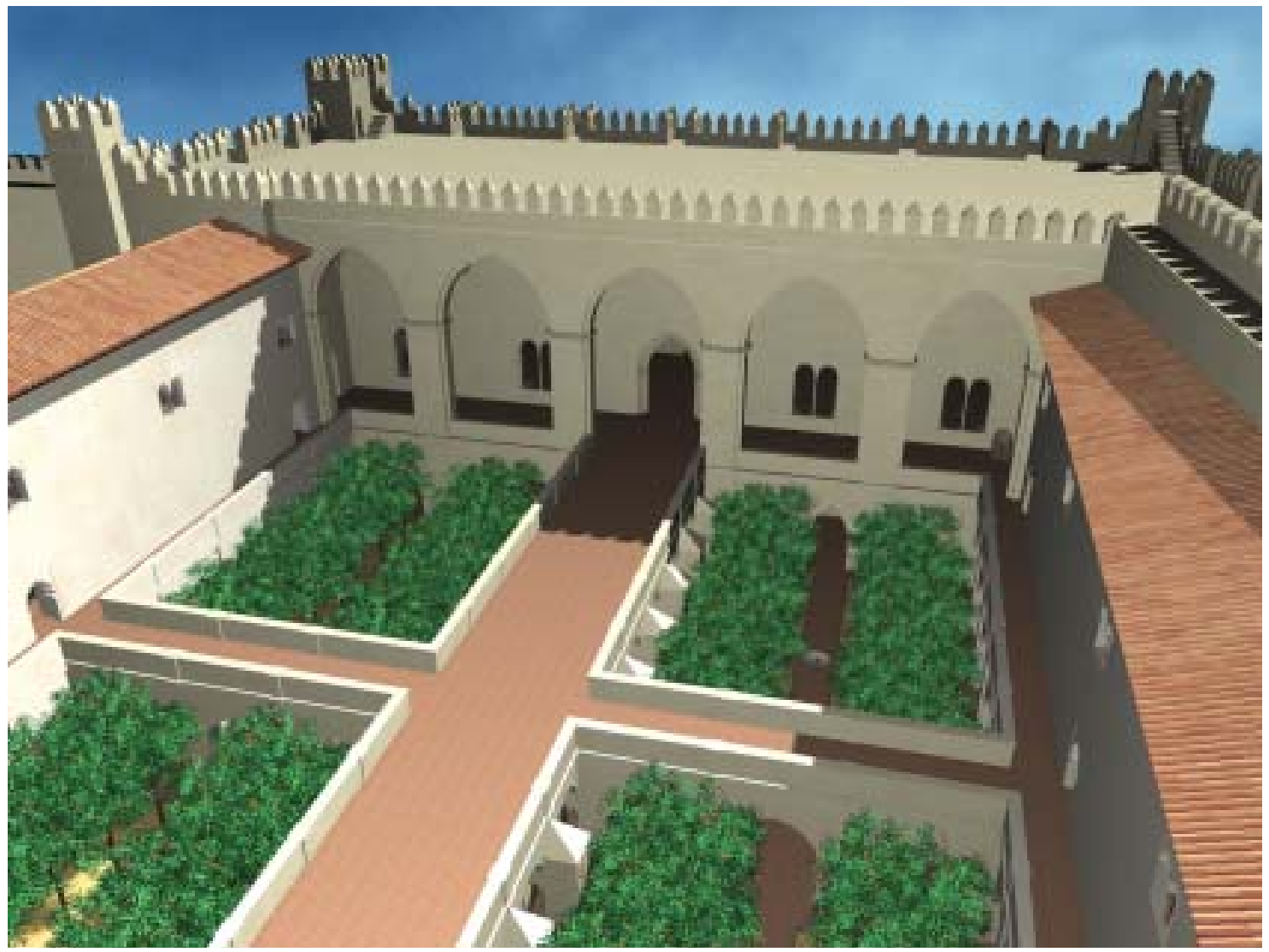


der que muchas de las hipótesis gráficas que hemos desarrollado son plausibles solamente en sus rasgos generales, es decir, en la descripción de los espacios y volúmenes, mientras que si hemos representado en muchos casos detalles de los que no existe ninguna certeza, ha sido solo con la finalidad de facilitar al observador la comprensión, siquiera a nivel de evocación, de la conformación espacial que en los distintos momentos históricos tuvo este singular conjunto.

Pese a los pocos elementos conservados del primitivo patio islámico, no cabe duda que nos encontramos ante una de las más original es soluciones nunca planteadas en la arquitectura residencial de al-Andalus. Sin duda lo más singular de este patio es su disposición en dos niveles y la ubicación de la vegetación en situación rehundida. En el nivel inferior se organizó un jardín, seguramente de crucero, con al bercas o rías en sus andenes principal es que definían otros jardines de crucero de segundo orden. Todo ello rodeado de pórticos en sus cuatro lados que sostenían las zonas de circulación del nivel superior: simples andenes en los lateral es y los pórticos de los sal ones en los frentes. LOS dos sal ones principales, situados en los testeros más cortos del patio, de proporción larga y estrecha, en nada diferirían de lo habitual en las casas y palacios andalusíes (fig. 14).

Tras la conquista de Sevilla por Fernando III pasaron a dominio del monarca los antiguos palacios reales islámicos de la ciudad. La estructura de estos pal acios, más concebi dos como residencias domésticas y para la vida placentera y el disfrute de sus patios y jardines que para una actividad cortesana protocolaria, debió plantear dificultades a sus nuevos habitantes. Por tal motivo se acometieron, seguramente en tiempos de su sucesor Alfonso $X$, importantes transformaciones que $I 0$ adecuaron a la nueva situación en la que cabe incluir las ambiciones imperiales de este monarca. Pese a ello se mantuvo la estructura del patio y la disposición de los dos sal ones enfrentados en sus dos extremos característica de las casas y palacios andalusíes. La zona norte, cuyo salón orientado al mediodía debía ser el principal del palacio islámico, no debió ni siquiera alterarse. La gran transformación se produjo en el lado meridional en donde, sin modificar la estructura básica del palacio, se dispusieron una serie de nuevos salones para dotarlo de mayor capacidad y prestancia. El salón meridional, se amplió hacia el patio dándole una mayor anchura y consecuentemente, el pórtico que le antecedía se desplazó igual mente hacia el norte. Este sal ón principal se rodeó de otros tres sal ones, uno paralel o al antes mencionado y otros dos perpendiculares al anterior que flanquean el conjunto. La otra gran transformación que sufrió el patio en este momento consistió en establecer una amplia comunicación entre el pórtico septentrional y los nuevos salones construidos en el lado sur al nivel de la planta baja (fig. 15). El resultado de esta disposición es una planta de palacio musulmán con uno de los lados hipertrofiado al envolver el salón de ese lado con tres crujías adicionales.

El Patio del Crucero toma su fisonomía actual tras las obras efectuadas después del terremoto de Lisboa de 1755 por el ingeniero Sebastián Van der Borcht. El terremoto debió afectar gravemente al palacio alfonsí, en especial al pórtico y al gran salón central que tuvieron que ser reconstruidos. Con el fin de dar mayor estabilidad a la estructura, los pilares del pórtico se diseñaron más robustos que los anteriores y con tal fin tuvieron que reforzarse los cimientos, macizándose partes de los arcos del pórtico gótico inferior. Todo el pal acio gótico cambió radical mente de aspecto. Se dispuso una fachada de estilo barroco, a base de un pórtico con cinco grandes arcos, soportados en gruesos pilares con dobles col umnas frontales (fig. 11). Tras el pórtico, se reconstruyó el salón con bóvedas baí das y a la bóveda central se la dotó de una linterna que sobresale en la terraza. Todas las fachadas de las demás crujías fueron remodel adas dotándol as de recercados de huecos, cornisas y cubiertas homogéneas. A demás, el patio se redujo notablemente de tamaño al construirse en su tercio norte el corredor de comunicación entre el A peadero, que se alarga con su actual último tramo, y el patio de la M ontería. Sin embargo, la más drástica transformación del patio vino de la decisión de enterrar todo el jardín bajo y subir el nivel de su suel o hasta el nivel de los salones.

El establecimiento de la hipótesis evolutiva de este singular conjunto arquitectónico presenta la dificultad ya aludida de su relativo buen estado de conservación por las labores permanente de mantenimiento, lo que ocasiona que los revocos cubran de manera homogénea la estructura interna de los muros haciendo casi imposible un análisis cronológico de paramentos. A pesar de ello, algunas zonas consienten lecturas parciales que nos han permitido plantear las hipótesis general es. Entre los temas de mayor interés, por su trascendencia para entender el concepto arquitectónico que presidió cada una de las fases históricas de este edificio, está el de la cronol ogía del crucero al to que organizaba el jardín hasta su radical trasformación en el siglo XVIII. Autores como Rafael M anzano han sostenido su cronología almohade aunque apuntando en algún momento una posi ble fase más tardía dentro de este mismo período (Manzano Martos, 1995; Manzano, 1995b). Por nuestra parte sostenemos que el jardín del pal acio al mohade no tuvo construcciones en su centro salvo en todo caso 


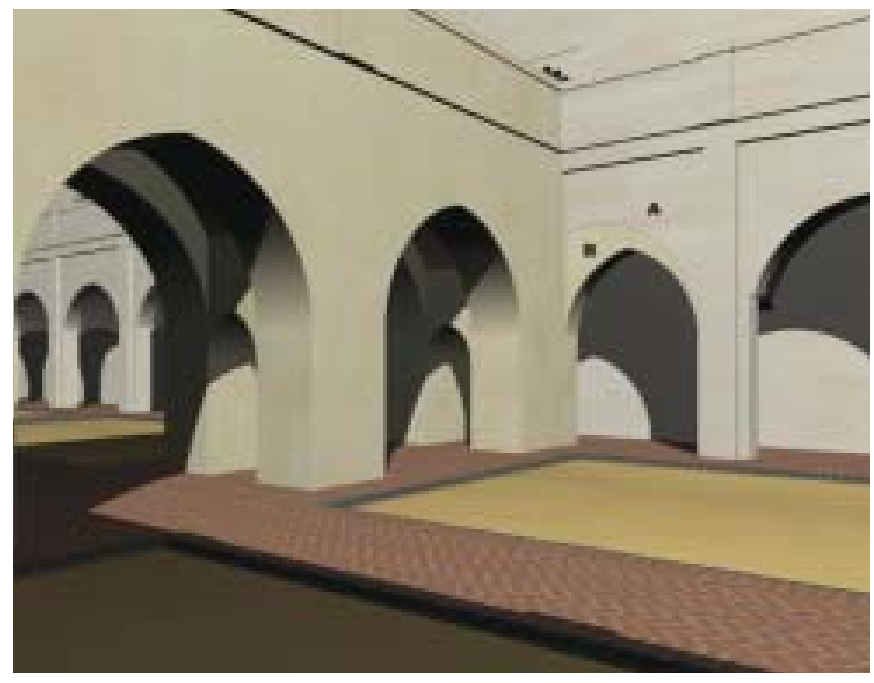

Fig. 13. La estructura del pórtico lateral vista desde el jardín: A.- fábrica islámica, B.crucero gótico.

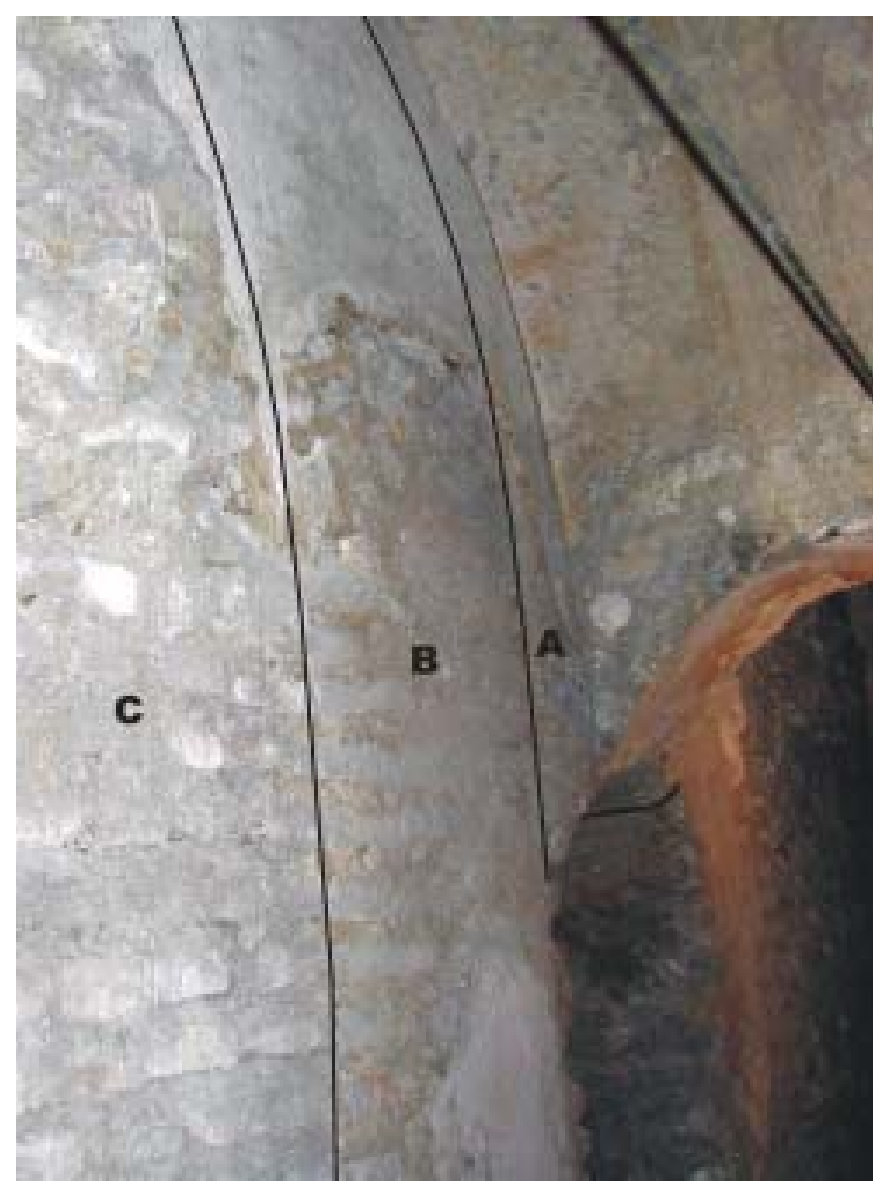

Fig. 12. Interpretación de las distintas fases en el pórtico oriental del jardín:A.fábrica islámica, B.- Fábrica gótica, C.- fábrica del siglo XVIII que tapia la arquería. al gún pabellón central aislado (fig. 14), ya fuera de fábrica o vegetal (A LmAGRo, 1999: 339).

Según nuestro entender, la otra gran transformación que sufrió el patio en época alfonsí consistió precisamente en establecer una amplia comunicación entre el salón septentrional y los nuevos salones construidos en el lado sur al nivel de la planta baja pues hasta entonces la única comunicación era a través de los andenes altos que corrían por los lados del patio. Estos andenes eran en cualquier caso de poca anchura, apenas $1.60 \mathrm{~m}$, y carecían de las condiciones para permitir un acceso protocolario desde la entrada al patio, que hemos supuesto situada en el lado norte, y los salones meridionales. Con el fin de establecer una amplia avenida de acceso a este lado sur se construyó un andén elevado sostenido por una estructura abovedada dentro de la cual se mantuvo una al berca al argada con pequeños corredores que discurren a los lados de ésta atravesando los pilares y formando dos pasadizos paral elos. Toda esta organización, que en total resultaría más ancha queel andén antiguo, obligó a reducir el tamaño de los arriates inmediatos a dicho andén central, produciéndose la asimetría que hoy se observa. Para dar mayor rotundidad al diseño se organizaron otros andenes transversal es formando un crucero en el nivel superior que posiblemente reprodujo el diseño de un crucero inferior que ya existía en el jardín islámico. Estos andenes transversal es y sus pilares de sostén alteraron la forma y disposición de los pórticos laterales al mohades al eliminar el pilar central de los mismos.

El análisis de paramentos en una zona no visitable y de difícil visión dentro de los pórticos laterales del jardín bajo, especialmente en el oriental, aportan la clave para entender la reforma realizada en época alfonsí (figs. 13, 14). Estos pórticos lateral es estaban formados por 12 arcos cada uno que en realidad son los frentes de bóvedas de eje perpendicular al muro de fondo. De hecho, es muy probable que en un primer momento no existiera tal corredor bajo sino una serie de nichos 0 al véol os cuyas bóvedas sostenían el andén superior. Con esta disposición no se producen empujes que pudieran provocar su vuelco hacia el patio. El apoyo de estas bóvedas se realiza en muros perpendiculares al que constituye el cierre lateral del patio, y que en una fase ulterior fueron tal adrados para generar un paso continuo cubierto. Los actuales arquillos formados con esas perforaciones no pueden ser originales ya que se apoyan en recrecidos claramente visibles adosados a la parte extrema de los muros transversal es que de este modo han adquirido forma de pilares con planta de cruz. Estos pilares presentan formas muy irregulares homogeneizadas por medio del revoco. 
La afirmación anteriormente expuesta, de que el patio primitivo no tuvo andén transversal a la cota del nivel superior, se basa en la observación de que original mente estos pórticos laterales no tuvieron solución de continuidad y menos en donde después se situó el andén que forma crucero. Para construir éste y dotarle de paso inferior al nivel del jardín, hubo que eliminar el pilar que coincidía en el eje transversal del patio, reduciendo la luz de los dos arcos contiguos con el fin de dejar espacio para los pilares del andén del crucero. Además, para dar acceso a la galería inferior que quizás se perforó en este momento, se dejó un arquillo coincidiendo exactamente con el pilar primitivo, que tuvo que ser cercenado en su parte inferior. Todo esto resulta hoy visible por el interior del pórtico del lado oriental en donde se aprecian los dos arcos primitivos y los real izados posteriormente con menor luz y altura (fig. 12), así como los recrecidos de los pilares, y la ruptura del central para abrir el paso. Todo está muy enmascarado por el enlucido posterior a esta reforma y sobre todo por el tapiado de toda la arquería que se realizó en el siglo X VIII para proceder a rellenar los cuatro grandes cuarteles del jardín hasta la cota del nivel superior. Además hay que remarcar que la disposición de los pilares y arcos de los pórticos laterales no guarda rel ación al guna con los del pórtico y anden central del crucero lo que constituye un dato más para asegurar su diacronía.

El estado actual de este patio no permite apenas discernir al visitante su larga y compleja evolución y ni siquiera al especialista le resulta fácil de imaginar. Tampoco creemos que pueda avanzarse mucho más en la recuperación de las estructuras medievales, pues tendría que hacerse a costa de transformar radicalmente el actual patio barroco, cosa que debe desecharse absolutamente. Sin embargo hoy las nuevas tecnologías nos permiten resolver, a través de la realidad virtual, al gunos de estos dilemas. El análisis arqueológico y las hipótesis de cronología en él basadas, nos permiten en este caso proponer una reconstrucción virtual de los distintos estados por que pasó el patio en su ya larga historia.

La informática ha puesto a nuestra disposición en los últimos años unos nuevos y poderosos instrumentos de visualización y representación que constituyen una revolución en el campo de la investigación del Patrimonio, al igual que lo son en otros muchos. Las posibilidades que ofrecen los programas de infografía son enormes. Visual ización de vistas perspectivas desde cual quier ángulo y condición, recreación de distintos estados o distintas soluciones, bien sea de formas volumétricas como de texturas, colores o iluminación, animaciones o visiones pano- rámicas, etc. También brinda la oportunidad de construir sistemas interactivos con participación del usuario en la elección de las distintas soluciones. La capacidad de recrear objetos, sobre todo arquitectónicos, que hayan sufrido grandes transformaciones o incluso ruina y desaparición constituye una de las más interesantes aplicaciones a las que se puede recurrir mediante los sistemas infográficos. Siendo el objetivo de los estudios arqueológicos el análisis de la cultura material, y constituyendo la arquitectura una de las expresiones más importantes y significativas de esta cultura, las posi bilidades de recrear visual mente estos restos cuando han sufrido grandes transformaciones, a veces difíciles de imaginar, supone claramente una ayuda potencial en nuestros trabajos.

Todos estos instrumentos tienen múltiples aplicaciones que podemos considerar dentro de dos grupos generales. U na sería la de facilitar la reflexión y la investigación sobre el patrimonio arquitectónico desaparecido. La recreación virtual obliga a considerar el elemento en toda su extensión, a plantearse soluciones para todos sus detall les y componentes y a reflexionar a la vista de las imágenes sobre nuestras hipótesis finales y por tanto, de trabajo. Resul ta igual mente un instrumento insustituible para tratar de entender las cualidades de los espacios originales, algo muy difícil de lograr sin estos métodos, pero que resulta fundamental en un análisis arquitectónico (Almagro Gorbea, Almagro Vidal, 2002). N uestra experiencia a este respecto ha sido muy interesante. D esde hace algo más de dos años, en el grupo de investigación sobre Arquitectura Islámica de la Escuela de Estudios Árabes hemos venido recurriendo a estos métodos tratando de dar forma a nuestras presunciones y de revisar los resultados como modo de profundizar en la investigación?2

Otra de las grandes aplicaciones de estos sistemas es la difusión de la información. Los métodos tradicionales de representación, mediante plantas, alzados y secciones siempre han resultado poco inteligibles para personas sin conocimientos ni experiencia sobre los sistemas de representación. Esto ocasiona que los frutos de la investigación no queden accesibles al público en general, no cumpliéndose con ello uno de los objetivos fundamentales de la investigación, cual es hacer Ilegar a la sociedad los avances del conocimiento que se van logrando. No cabe duda de que éste es uno de los campos que más interés ofrece y uno de los que más rentabilidad social puede aportar, hasta el punto de hacer pensar que en un futuro cercano resulte casi

\footnotetext{
${ }^{2}$ Los trabajos de infografía de la reconstrucción del Patio del Crucero han sido real izados por Ana Almagro Vidal y M iguel González Garrido bajo la dirección de J osé A ntonio Fernández Ruiz.
} 
obligado recurrir a estos instrumentos para dar a conocer los resultados de nuestras investigaciones.

El desarrollo de la aplicación de estos sistemas merece una investigación y reflexión específica pues ante el hecho de disponer de instrumentos hasta ahora casi desconocidos, debemos pensar que su correcto uso puede dar magníficos resultados, pero un empleo inapropiado también puede generar productos inadecuados y, con ello, reacciones negativas. A este respecto debe tenerse en cuenta que la utilización de estas aplicaciones informáticas se ha difundido de una manera muy amplia entre técnicos y profesionales ajenos a nuestros estudios que, ante la demanda social de este tipo de representaciones, si enten la lógica tentación de aportar imágenes que en muchos casos carecen del adecuado soporte científico en su gestación. El problema puede venir tanto en lo que respecta a la concepción general de las hipótesis como a intentar dar solución a cuestiones de detalle, como puedan ser las texturas, materiales y colores 0 en la búsqueda de visiones "fotorrealistas" sobre las que no existan evidencias y que pueden producir sensación de falsedad en las propuestas. Por esta razón no podemos mantenernos de espal das a estos métodos de trabajo excusándonos en que son fuente de fal sedades. Será responsabilidad de quienes trabajamos en el campo de la investigación arqueológica y arquitectónica aportar el necesario rigor a las propuestas. Porque si no lo hacemos desde el campo científico, sin duda otros sin las bases adecuadas lo harán y en cualquier caso, este tipo de representaciones Ilegarán a la sociedad, porque la sociedad las está demandando.

Sobre estas bases hemos realizado ya varias experiencias, la primera con el estudio del Alcázar omeya de A mman, para el que realizamos una reconstrucción infográfica completa presentada en forma de aplicación interactiva que quedó incluida en la publicación científica de nuestros estudios en forma de CDR om (A LMAGRO, J IMÉN EZ, N AVARRo, 2000). El segundo trabajo hasta ahora concluido ha sido éste del A lcázar de Sevilla, encaminado a la instalación de un sistema de visualización interactivo que permite a los visitantes del monumento conocer las distintas fases por las que ha pasado este singular edificio.

El análisis arqueológico se revela de primordial importancia como base para plantear hipótesis de este género y tendrá sin duda que potenciarse y asumirse de manera general izada para éste y otros fines en los estudios del patrimonio arquitectónico.

\section{Bibliografía}

Almagro A., 1999, El Patio del Crucero de los Reales Alcázares de Sevilla, A I-Q antara, XX, pp. 331-376.

Almagro A., 2000, Planimetría del A lcázar de Sevilla, Granada, (carpeta con 40 planos).

Almagro A., Jiménez P., Navarro J., 2000, el Palacio Omeja de A mman III, Investigación arqueológica y restauración, 1989-1997, Granada.

Almagro A., ORIhuela A., 1995, El cuarto Real de Santo Domingo, en N avarro J. (ed.), Casas y palacios de al-A ndalus. Siglos X II y XIII, Barcelona, pp. 241-253.

Almagro A., Orihuela A., 1996, Investigación y propuesta de recupe ración del Cuarto Real de Santo Domingo (Granada), en III International Congress on Restoration of Buildings and A rchitectural H eritage ( $\mathrm{G}$ ranada 20-25 may 1996), Granada, pp. 573-577.

AlmAgro A., ORIHUELA A., 1997, Propuesta de intervención en el Cuarto Real de Santo Domingo (Granada), L oggia, 4, pp. 22-29.

Almagro Gorbea A., Almagro Vidal A., 2002, La Expresión Gráfica en el análisis del Patrimonio: El Patio del Crucero del Alcázar de Sevilla, en $A$ ctas del IX Congreso Internacional de Expresión Gráfica A rquitectónica. EGA 2002, ReVisiones: Enfogues en docencia e investigación, A Coruña, pp. 517-522.

Gómez-Moren o Martínez M., 1966, Granada en el siglo XIII, Cuadernos de la A lambra, 2. pp. 26-33.

M AN ZAN O MARTOS R ., 1995a, Casas y pal acios en la Sevilla al mohade. Sus antecedentes hispánicos, en N Avarro J. (ed.), C asas y Palacios de al-A ndalus, S. X II y X III, Barcelona, p. 342.

ManZANO R., 1995b, El Alcázar de Sevilla: Los palacios almohades, en VALOR M. (coor.), El último siglo de la Sevilla islámica, Sevilla, p. 110.

MuRPhY, J.C., 1987, Las Antigüedades A rabes en España. La Alhambra, Granada.

ORIh UelA A., 1997, Casas y Palacios N azaríes. Siglos X III-X V, Barcelona, pp. 315-333.

Pavón MaLdonado B., 1991, El Cuarto Real deSanto D omingo deG ranada, Granada. 